\title{
Models of regional business spatial community management
}

Tomasz Turek, Czestochowa University of Technology, Poland, turek@zim.pcz.pl

\begin{abstract}
Online communities are no longer the domain of people. Due to changes in economy, the free flow of capital and people, and the processes of globalization, more and more often enterprises appear in communities. This applies in particular to the organizations based on the resources of information and knowledge. Relations of this type are called business communities. A specific form of this type of relation is projects undertaken within geographical areas: cities, states, and provinces. Due to the bonding agent - the geographical area - they are based on spatial information GIS systems. Projects arising this way can be called Regional Business Spatial Community - RBSC. In RBSC it is possible to perceive the features of network organizations and virtual organizations (VO). Network organization features are the result of geographical dispersion, established relations, common goals, and mutual synergic replenishment. VO features are a result of the role of information resources, temporariness, fuzziness, and the ability to reconfigure. Due to the characteristics of network organization and VO, RBSC management becomes a problem. The question is who has to make decisions and on what conditions in such projects. Possible scenarios are: democratic governance, the establishment of common unit coordinating and managing, ad-hoc flexible management, or the appointment of the subject responsible for the management.
\end{abstract}

Keywords: business community, regional management, regional business spatial community.

\section{Introduction}

The era of information and knowledge is characterized by intensive use of information resources in virtually every area of life. An important feature is the use of social media and the formation of communities. Social media plays an important role, not only in the area of interpersonal communication, but also as their potential is perceived in achieving business goals. Virtual communities on the Internet are the blueprint for the formation of business communities. Dispersed organizations within the framework of the implementation of specific business objectives can connect into a community with different levels and strength of the relationship. A specific form of business community is the relationship in which the binding force is a defined geographical area: city, region, and state. A community of this type can be described as Regional Business Spatial Community (RBSC).

Due to the nature, area of activity, and intensive use of information technology, RBSCs have characteristics of both network and virtual organizations. In this context, the question arises, who and on what basis should manage the community? There are different scenarios. The aim of the article is to present potential solutions and management models for an RBSC. 
The first part of the article explains the essence of RBSC in the context of current publications and research. The next part highlights the similarities of RBSC to network and virtual organizations. The last part of the article is a presentation of possible models and scenarios in the management and decision-making within an RBSC.

\section{Definition of RBSC}

Online communities (virtual communities) are a phenomenon of the age of information and knowledge. People use information and communication technology (ICT) in order to establish contacts and relationships in the network. ICT becomes a catalyst for making relations (Štefko, Dorčák, \& Pollák, 2011). People are willing to join virtual communities, because they become a form of interaction. The Internet thus becomes the medium of communication. In addition, the social networking site allows the creation of groups and circles that are centered around a particular purpose, initiative, or event. A virtual community is formed in parallel to a traditional community in the real world. Often however, it allows for the creation, maintena ce, and development of relationships that would not survive in the real world (see more: The Business 2008 and IRMA 2016).

Business communities can be formed in a similar fashion. Enterprises - like people - feel the need to contact other companies, institutions, and societies. These relationships are not established by chance. Partners are selected with great care. Business communities are formed around common interests, projects, and initiatives. After completion of the project, relationships can be suppressed, until the advent of the next of this type of occasion.

A specific form of virtual business communities are communities concluded by entities implementing the objectives and tasks in the area of a region, city, or province. The factor binding companies is, in this case, a defined geographical area. Enterprises scattered in this area realize their own business goals, but they are interdependent. Relationships of this kind might be called Regional Business Spatial Community (RBSC).

The Regional Business Spatial Community is a proposal for an electronic enterprise based on the Internet, with its aim of creation of shared informational resources of land development nature. The community can be approached as an electronic consortium which is composed of the entities that operate within the shared environment. (Jelonek, Stępniak, Turek 2013, p.84).

Elwood (2006b), as well as Kenyon and Kincaid (1999) indentified the role of linkages between local business communities and residents.

The concept stated by Ellwood (2006b) is similar to the concept of RBSC: "The particular goals of these community organizations are focusing on housing improvement, better access to affordable housing, employment training and job development, youth and family support, crime reduction, retention of employers, and prevention of residential and business displacement" (Elwood 2006b, p.17).

The RBSC might include a number of entities, including:

- Selected entities of public and local administration,

- Enterprises which supply utilities or manage the infrastructure in the region, 
- Organizations interested in development of the region,

- Inhabitants of city, region, state, or voivodeship.

The basic relationship linking these actors within the community is a specific geographic area. Enterprises operating in the area can provide information about ongoing projects and investments. RBSC becomes a platform for exchange of information. It enables matching of resources and leads to networking and cooperation.

Realization of investments and projects depends not only on other companies (which may be competitors or partners), but also on the offices of government. This involves issuing of licenses to conduct business, checking compliance of construction with the local development plan, etc. At the moment, most of these tasks may be performed with solutions such as the Public Information Bulletin (www.bip.gov.pl) and Electronic Platform for Public Administration Services (epuap.gov.pl). RBSC can be integrated with these services and therefore be an element of connecting business communities, offices, and residents.

Additional institutions that could potentially be included within a RBSC include research units, universities, and laboratories. The results of research and experience of an easier way may be published and implemented in life. Research institutions are also an important element of advisory for planned investments in the region. RBSC thus allows for easier integration and interpenetration of science and business.

At the end of the chain of processes carried out in RBSC are residents. Coordination between enterprises, offices and research institutions makes sense only if the benefits are reflected in improved living standards. On one hand, the mutual exchange of information, data, and knowledge contributes to the strengthening of cooperation, complementarity of resources, synergies and thus more efficient business processes. On the other hand, the result will be benefits for residents. Local projects will be implemented more efficiently and at a lower cost. Investments will be better planned, so the time of their execution will be faster and without unnecessary downtime. This, in turn, can contribute to greater satisfaction with life in the city and the region. Well-organized relationships in business communities can reflect in a better perception of the region and the emergence of new investors.

A factor connecting entities in RBSC is geographical area. Due to this factor, it seems natural to make an electronic collaboration platform based on GIS. Such systems allow the recording of data about the spatial characteristics. This data comes from community participants. They can take various forms and involve different aspects. The task of RBSC platform is the integration and unification, which will allow their joint use in the process of investment planning and management of the region.

One should be aware that the information resources are currently a strategic factor for any organization. Participants of RBSC will therefore not provide data in a chaotic or rash way. Only the information that is necessary from the point of view of certain interests will be shared. They should be seen as a kind of specific costs that can be incurred only after achievement of specific revenue and hence profit for the organization.

Information resources made available by various entities of community are other thematic layers. Analysing such complex data from a variety of perspectives allows one to make rational 
decisions. Each of the entities participating in the RBSC may in its own way use collectively gathered information resources. In this way, specific knowledge of social networking, the use of which would be impossible in the case of classical functioning detached from the community, is created.

From the point of view of RBSC, contemporary GIS tools may be applied in many cases, for example:

- Spatial inventory of diverse types of resources (owned and belonging to third parties); different layers can expose various classes of objects considering many criteria; additionally it is possible to link the objects with additional text descriptions available by hyperlinks; the description can be retrieved from other information systems;

- Integrated approach for geospatial intelligence; predictive simulation of new objects on the map ensuring safety and regulatory compliance; it is possible thanks to i.a. analysis for collision avoidance, estimation of costs of investment or analysis of influence of the planned investment on environment;

- Reserving the area for investments by manually applying objects on the map; the application of object is valid until the decision about approving or rejecting proposed investment; this feature can also be used to generate investment documentation for public authorities (Jelonek, Pawełoszek, Stępniak, \& Turek, 2015, pp.991).

The conceptual model of RBSC is presented on Figure 1.

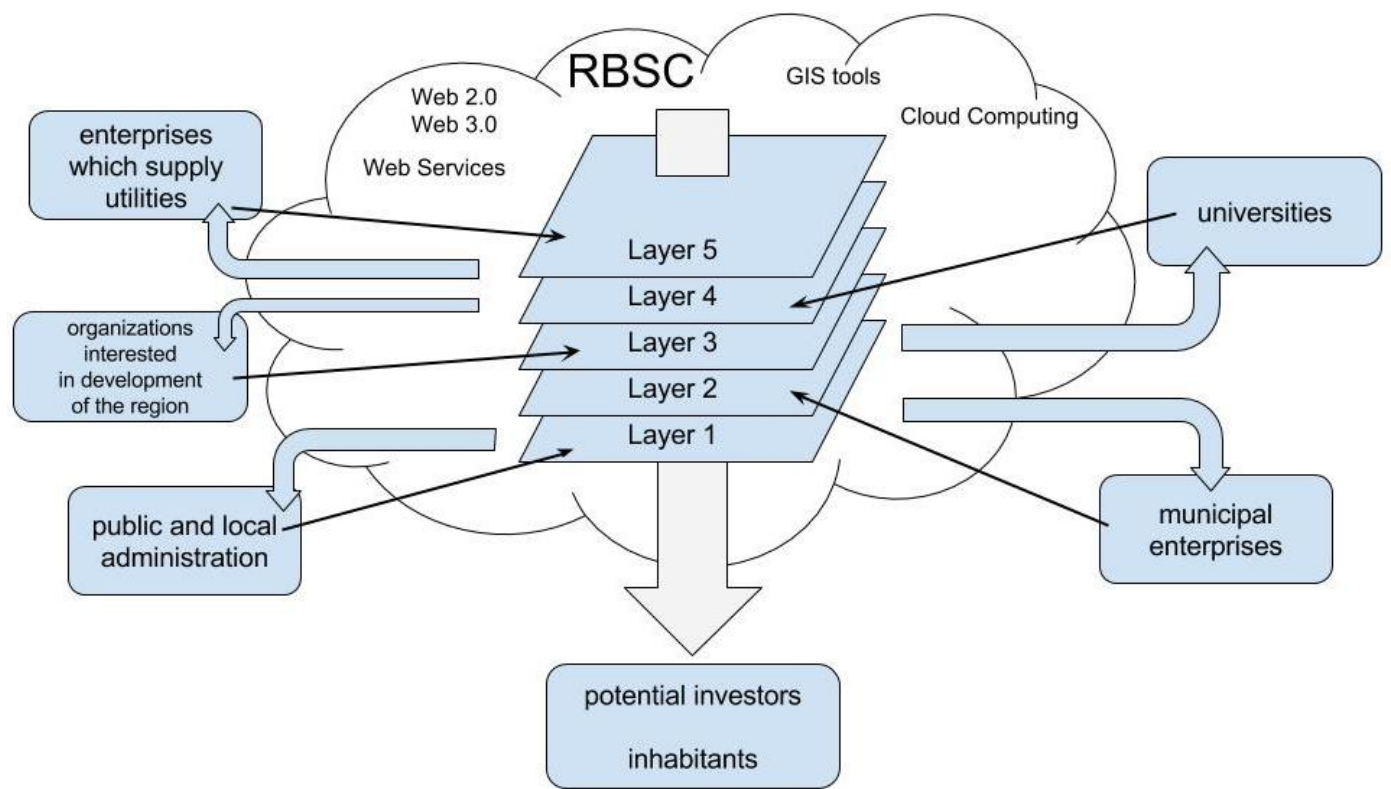

Figure 1. The conceptual model of RBSC

As it is shown in a picture, you can see that RBSC is a concept based on many different ICT solutions, such as cloud computing, GIS tools, web services, Web 2.0, and Web 3.0, . These solutions let community's members provide information resources, which create successive thematic layers. For example, offices can provide geodetic maps and resources Enterprises which supply utilities can share information about the progress of the infrastructure (cables, water 
supply, water pipelines, etc.). Universities and research institutions have the opportunity to share research results and organizations interested in development of the region provide strategies, missions, and goals. RBSC's task is to enable the collection and analysis of data from different entities that has varying formats and isfrom many different perspectives and points of view. As a result, it is then possible to obtain synergy data. RBSC's beneficiaries are the entities creating it. It is also possible to share selected resources to potential investors and residents. A common feature of cooperation in the framework of RBSC is specified geographical area, and thereby the spatial information resources.

Spatial information resources are data that may be assigned with spatial attributes, which is a geographical location of objects in the information systems, although spaces defined mathematically can also be used. These objects can then be visualized on maps. The ability of displaying the location of objects along with their description on a map, e.g., through the use of hypertext technology, can significantly facilitate the description of selected aspects of business operations (Stępniak, Turek 2014, p.100).

\section{RBSC as a network and virtual organization}

The essence of RBSC can be seen from different points of view. Depending on the adopted perspective, the elements of the network enterprise and virtual organization can be perceived. Modern companies increasingly turn to the network. This is because they cannot carry out specific tasks and projects on their own.

Corporate purposes, which may not be achieved by individual actions, are often implemented as a result of producing a synergistic potential of cooperating entities (Grabowska, 2014). Thus, the collaboration between companies is becoming an inherent feature of management, and the resulting structures often take the form of network organization or inter-organizational networks. In the first case, the company formed a kind of the joint venture agreement, not leading to the creation of any structure or legal entity. The network in this case is the agreement. The second category makes up the network that does not stop at the conclusion of the contract, but leads to the creation of new forms of cooperation, which as a new legal entity acquires rights and incurs liabilities in its own name (Niemczyk \& Stańczyk-Hugiet, 2012).

Cooperation in the form of networks offers great opportunities for both the configuration and coordination of cooperating organizations and individuals. Additional opportunities include the benefits arising from the effect that arises from the creation of organizational links, integrating a number of dispersed activities, to expand the reach and impact area, as well as a better flow of not only knowledge, but also skills, new ideas, and experiences. This brings an increase in the efficiency of network organization in achieving its objectives and allows to build a positive potential, which is a source of creative and innovative solutions decisive for the success of achievements across the organization network (Sułkowski 2013).

Development of cooperation between enterprises and inter-organizational networks may have different character. Czakon (2005) pointed out the most important directions in this area:

- Competition among groups of companies resulting in the emergence of a market competition of whole communities instead of competition of individual companies; 
- Restructuring of large organizations linked to competitive pressure, the requirements of shareholders and the need of flexibility;

- The phenomenon of interaction among many enterprises as commonly found in economy practice.

The consequence of the dispersion of the organizational structure within a single legal entity, a network organization, or a cross-organizational network is dispersal of areas of generation and information processing.

A VO is more or less an extensive network of independent entities operating in the real world, which, in order to connect and exchange resources, use ICT technologies.

A VO is always a form of partnership. In the literature many definitions of VO can be found. Mowshowitz (1994) was the first to use this term. Since then, there have been many definitions of a general and narrow nature.

Reinicke (2011) provides a good example of a narrow definition:

VO's (virtual organizations) refers to a new organizational form characterized by a temporary or permanent collection of geographically dispersed individuals, groups or organization departments not belonging to the same organization - or entire organizations, that are dependent on electronic communication for carrying out their production process (p-p. 50-51).

Each VO has a set of inherent characteristics which distinguish it from other forms of relationships between enterprises. These features can also be seen in RBSC. These are:

- Delocalization - RBSC works within a given geographical area: region, city, province, or state. Co-creating entities, however they are scattered, are in different places of area. RBSC as a VO is a platform linking these entities on the basis of information resources, social knowledge, etc.

- Temporalization - RBSC is a temporary structure. Entities may be combined in the context of specific goals, projects, and investments. After the investment, interests of individual communities may disintegrate and merge under the new ventures.

- Dematerialization - RBSC is a structure that does not have physical characteristics.It is a creation that functions on the Internet, based on a type of cloud solution. Shared and synergistic resources - information, data and knowledge - are also immaterial. The effects of synergy are also intangible, but they become the basis for decision-making, coordination of investments, and projects.

- Individualization - Produced within the RBSC relationships and circles of community, goals are not repeated. Goals are formed in an individual manner, taking into account the specifics of the project or investment. Individualization is also reflected by taking into account the specific characteristics of employees and managers cooperating in the framework of defined objectives of RBSC.

- Non-institutionalization - RBSC does not have a material nature. Neither does the relationships between the actors. Because of this, it is hard to see the structure of an RBSC and find the classic attributes of an organization that works in the real world. 
- Asynchrony - RBSC is based on ICT solutions. Due to this fact, the communication is asynchronous. Information resources do not need to be read, processed, and published at the same time (Nami, 2008).

Development of a VO also provides a series of benefits for entities involved in its formation. This also applies to RBSC. Some benefits of VOs include the following:

- Saving time.

- Spreading costs and risks with partners.

- Improving quality factors such as performance and flexibility, the exchange and sharing of knowledge, and marketing in high scale (global networks).

- Matching VOs with dynamic changes in marketing.

- Access to new technology and new customers.

- Access to new markets through partnership.

- Improving access to financial resources (Nami, 2008).

A ynthetic approach of features of network organization and virtual organization in RBSC is presented in Table 1.

Table 1. Synthetic approach of features of network organization and virtual organization in RBSC

\begin{tabular}{|c|c|}
\hline \multicolumn{2}{|r|}{ Regional Business Spatial Community } \\
\hline $\begin{array}{c}\text { Characteristics } \\
\text { of network organization }\end{array}$ & $\begin{array}{l}\text { - } \text { dispersal of individuals participating in the community; } \\
\text { - } \text { cooperation in the context of specific initiatives, projects; } \\
\text { - combining and complementing resources; } \\
\text { - } \text { use of synergies; } \\
\text { - positive effects for all community participants; } \\
\text { - eliminating imperfections of organizations through cooperation with other } \\
\text { - } \text { actors; } \\
\text { - } \text { co-opetition (competition and cooperation); } \\
\text { - commonization of the activities of participants; }\end{array}$ \\
\hline $\begin{array}{c}\text { Characteristics } \\
\text { of virtual organization }\end{array}$ & $\begin{array}{l}\text { - cooperation based on information and communication technology; } \\
\text { - the main resource is information; } \\
\text { - decentralization of knowledge; } \\
\text { - the formation of social knowledge; } \\
\text { - temporality; } \\
\text { - } \text { the lack of clearly defined borders; } \\
\text { - easy entry and exit; } \\
\text { - based on real participants creates an unreal existence; } \\
\text { - } \text { loss of hierarchy or no hierarchy; } \\
\text { - } \text { ability of transformation and reconfiguration; }\end{array}$ \\
\hline
\end{tabular}


In practice, projects such as RBSC take the form of a dual organization and have a resemblance to both network and virtual organizations (Hughes \& O'Brien, 2001). Network characteristics relate more to real business processes connected with the implementation of objectives for the inhabitants of the region, business development, projects, etc. Virtual features follow information processes related to the exchange and sharing of information resources and the creation of social knowledge (Al-Ghamdi \& Al-Ghamdi, 2015; Hosseini, Zuo, Chileshe, \& Baroudi, 2015).

\section{RBSC management - selected aspects}

Due to the characteristics of network organization and virtual organization which are perceived in RBSC, an important aspect is the management of this type of entity. It is necessary to answer the question of whether to manage the organization according to the rules of a network organization or a virtual organization. Typical network organizations often have a wellestablished and fixed structure, which is governed by specific laws. This approach is common, for example, in the model of a franchise, where management and decision-making within the network is centralized. The situation is different in virtual organizations. They do not have a tangible structure, and thus do not have a hierarchy. Management is distributed and smooth.

In the case of network organizations, an important factor in the management of the network is its architecture. Architecture means the number of entities forming the network and connections and relationships among them. In this context, a distinction is made betwee dispersed and centered networks. Centered networks are characterized by a large number of links. In dispersed networks, the number of such relationships is relatively small. RBSC, due to functioning within relatively small areas, is more like a centered network.

An issue of major importance seems to define the essence of network management capabilities. The role of network management is to transform from a given initial state to the desired target state within a specified period of time. The desired state should be understood as target number of network participants, the type of network participants, and the structure of links among them. It should be diagnosed who and how can transform a group of entities related with one another by direct and indirect relationships of a cooperative character into a desired state (Pierański, 2013).

Among the concepts of business network management, two opposing trends dominate. One assumes that network structures are impossible to be formed by a single organization, and the network is managed by all entities forming it, as if on democratic principles. The second trend assumes that network should be managed by one company. From the nature of things, this role should be assigned to the organization with the greatest potential. A peculiar form of compromise here is the appointment of individuals managing and coordinating a network in which employees of entities in the network can participate.

When analyzing the management aspects of RBSC from the perspective of virtual organization, one should pay attention to the lack of a clear hierarchy and division into managers and contractors of commands. As a virtual organization, RBSC is based on the management of information resources, knowledge management, social networking, and is formed as an added value of cooperation. 
A key role in virtual organizations is the integrator,. The integrator serves as a strategic center for a VO. Its presence in a VO is necessary mainly because of the need to ensure proper cooperation among the diverse communities, autonomous entities, and complementary entities.

The integrator is also responsible for knowledge management within the VO. The integrator should make every effort to create the right conditions for sharing knowledge among cooperating entities within the VO. The integrator promotes the sharing of knowledge among cooperating actors, and promotes best practices and standards of cooperation. The integrator creates a knowledge management system and encourages entities to learn to cooperate. Through cooperation, the entities would gain new knowledge and advice. In addition, the integrator creates its own knowledge resources with a capacity of partners (central knowledge repository), exchanges knowledge with other integrators of virtual organizations, and distributes the accumulated wealth of knowledge among the parties after the end of $\mathrm{VO}$ in accordance with the legal requirements (Dziembek, 2008).

On the basis of the proposed approaches to the network organizations management and VO it is possible to formulate concepts (models) of RBSC management. The following scenarios are possible:

- RBSC is managed by a single entity - The role of the decision-making entity adopts a participant of the project with the greatest potential. The potential is determined on the basis of economic indicators, involvement in the creation of RBSC, or other factors;

- RBSC is managed in a democratic way - In a RBSC, there is no specific decision-making entity, so management is done in a collective manner. Decisions are taken by consensus and general common good and common goals. The RBSC becomes by it "self-managed";

- RBSC is managed by a coordinating unit - A scenario resulting from the concept of collective management. RBSC participants decide to appoint a management unit, which is composed of persons belonging to all parties. The coordinating unit makes decisions affecting the shape of cooperation;

- RBSC managed by ad-hoc - In this model there is no clearly defined entity responsible for the management of the RBSC. Depending on the projects and investments, management can be given to those entities which are most involved in the implementation. After the investment, decision-making tasks can be passed to another participant of the RBSC;

- RBSC is managed by a non-profit entity - Because of concerns that commercial companies might try to exploit cooperation in RBSC for their own purposes, management tasks can be entrusted to entities not conducting commercial activities. An entity which has a natural predisposition for this are organs of local administration or regional authorities.

The proposed scenarios are an attempt to identify possible solutions to the management of an RBSC. In business practice, other solutions may arise, which are often a hybrid of concepts outlined in the article. They take into account the specificity of the region, experience, and potential of participants in the community. 


\section{Conclusions}

Projects based on the concept of local business communities become an integral part of the economy. Enterprises are linked together and, increasingly, the main binder of cooperation is the defined geographical area.

The cooperation of enterprises, local and public administration, and other institutions in terms of cities and regions may take the form of the proposed concept RBSC.

As each and every RBSC project must be managed in some way, there must be a decisionmaking center, which forms relations and making decisions in the community. This article proposes possible scenarios for managing the business community. The proposed solutions are based on assumptions and concepts related to network organizations, virtual organizations, and the author's insights/observations.

At the moment, RBSC is a project at the conceptual stage, so there are no full results from research in this area, which could be helpful in choosing one of the proposed scenarios.

It is possible to use the results of the initial pilot studies. A research unit, which employed the author of the article in the years 2013-2016, led efforts on the possibility of full implementation of the RBSC concept. This research was conducted in the region of the city of Czestochowa, Poland.

The results indicated that the most desirable model for managing RBSC was the last of the proposed scenarios. As the initiator, the coordinator, and the unit responsible for the management of the most common function, the city council is the most likely candidate to act as the initiator. It not only has predispositions, but it is obliged to this by regulations and laws. City councils are interested in finding investors. City councils also have the necessary information and organizational capacity.

Moreover, the city council is a non-profit institution and will not raise suspicions that obtained privileged position in management and decision-making will affect the unfair actions and desire to achieve profits at the expense of other members of the community.

\section{References}

Al-Ghamdi, H.A.K., \& Al-Ghamdi, A.A.K. (2015). The role of virtual communities of practice in knowledge management using Web 2.0. Procedia Computer Science 65, 406-411.

Czakon, W. (2005) Istota relacji sieciowych przedsiębiorstwa. [The essence of the company's network relations], Przegląd Organizacji, vol.9

Dziembek, D. (2008). Rola integratora $w$ organizacji wirtualnej. [The role of the integrator in virtual organization], [in:] Kisielnicki J. (ed.) Informatyka dla przyszłości. Naukowe Wydziału Zarządzania Uniwersytetu Warszawskiego.

Elwood, S. (2006a). Beyond cooptation or resistance: Urban spatial politics, community organizations, and GIS-based spatial narratives. Annals of the Association of American Geographers 96(2), 323-341. 
Elwood, S. (2006b). Beyond Cooptation or Resistance: Urban Spatial Politics, Community Organizations, and GIS-Based Spatial Narratives, PPT presentation, http://dusk.geo.orst.edu/virtual/2007/elwood_2006.ppt

Grabowska, M. (2014). Współdziałanie przedsiębiorstw w perspektywie sieciowej. [The cooperation of companies in the perspective of the network], Zeszyty Naukowe Politechniki Śląskiej, Seria Organizacja i Zarządzanie z. 76, p.53-54

Hosseini, M.R., Zuo, J., Chileshe, N., \& Baroudi, B. (2015). Evaluating virtuality in teams: A conceptual model. Technology Analysis and Strategic Management 27(4), 385-404.

Hughes, J. A., J. O'Brien, et al. (2001). Some "real" problems of "virtual" organization. New Technology, Work and Employment 16(1)

IRMA (2016), Social media and networking: Concepts, methodologies, tools, and applications, IGI.

Jelonek, D., Pawełoszek, I., Stępniak, C., \& Turek, T. (2015). Spatial tools for supporting regional e-entrepreneurship. Procedia Computer Science, 65, 991

Jelonek, D., Stępniak, C., Turek, T (2013). The concept of building regional business spatial community. ICETE 2013. 10th International Joint Conference on e-Business and Telecommunications. Proceedings. 29-31 July, Reyklavik, Iceland. SCITEPRESS Science and Technology Publications.

Kenyon, D.A., \& Kincaid, J. (1999). Competition among states and local governments: Efficiency and equity in American Federalism. The Urban Institute Press: Washington D.C.

Leonard-Barton, D. (1995). Wellsprings of knowledge: Building and sustaining the sources of innovation, Boston, MA: Harvard Business School Press.

Mowshowitz, A. (1994). Virtual organization: A vision of management in the information age. The Information Society, 10(4).

Nami, M. R. (2008). Virtual organizations: An overview, IFIP - The International Federation for Information Processing, 288, 211-219.

Niemczyk, J., Stańczyk-Hugiet, E., Jasiński, B. (2012). Sieci międzyorganizacyjne. Współczesne wyzwanie dla teorii $i$ praktyki zarzadzania. [Inter-organizational networks. Today's challenge for management's theory and practice], C.H. BECK, p.9

Pierański, B. (2013). Koncepcje zarzadzania siecia przedsiębiorstw. [Concepts of the enterprises' network management], Czasopismo Logistyka, nr 5.

Reinicke, B. (2011). Creating a framework for research on virtual organizations. Journal of Information Systems Applied Research (JISAR), 4(1), 50-51.

Štefko, R., Dorčák, P., Pollák, F. (2011). Virtual social networks and their utilization for promotion. Polish Journal Of Management Studies, 4.

Stępniak, C., \& Turek, T. (2014). Integration of spatial information resources on the example of utility companies in Częstochowa Region. Online Journal of Applied Knowledge Management,2(2). 
Sułkowski, Ł. (ed.). (2013). Zarzadzanie organizacjami sieciowymi. [Management of the network organizations], Przedsiębiorczość i zarządzanie, TOM XIV, Zeszyt 13, Część 1, 2013, p.5.

The business impacts of social networking (2008), http://www.business.att.com/content/whitepaper/WPsoc_17172_v3_11-10-08.pdf

Travica, B. (1998). Organizational virtualness. VoNet Workshop, http://virtualorganziation.net/.

\section{Author Biography}

Tomasz Turek - employed as Assistant Professor at Czestochowa University of Technology, the Faculty of Management, Business Informatics Department. Research interests are related to cooperation of companies in the electronics markets. As didactic employee he lectures in Management Information Systems and Process Management. 